Portland State University

PDXScholar

1975

\title{
Validation of the Preschool Speech and Language Screening Test
}

Susan Jane Packouz

Portland State University

Follow this and additional works at: https://pdxscholar.library.pdx.edu/open_access_etds

Part of the Speech and Hearing Science Commons, and the Speech Pathology and Audiology Commons

Let us know how access to this document benefits you.

\section{Recommended Citation}

Packouz, Susan Jane, "Validation of the Preschool Speech and Language Screening Test" (1975).

Dissertations and Theses. Paper 2293.

https://doi.org/10.15760/etd.2290

This Thesis is brought to you for free and open access. It has been accepted for inclusion in Dissertations and Theses by an authorized administrator of PDXScholar. For more information, please contact pdxscholar@pdx.edu. 
AN ABSTRACT OF THE THESIS OF Susan Jane Packouz for the Master of Science in Speech Communication: Emphasis in Speech Pathology/Audiology presented May 29, 1975.

Title: Validation of the Preschool speech and language Screening Test.

APPROVED BY MEMBERS OF THE THESIS COMMITTEE:

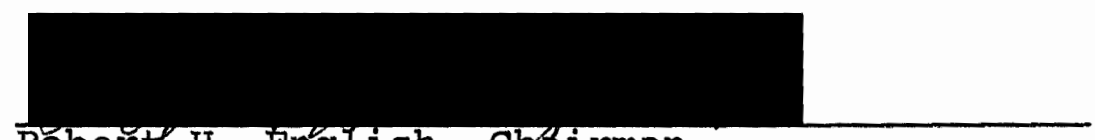
Röbert H. English, Chzirman
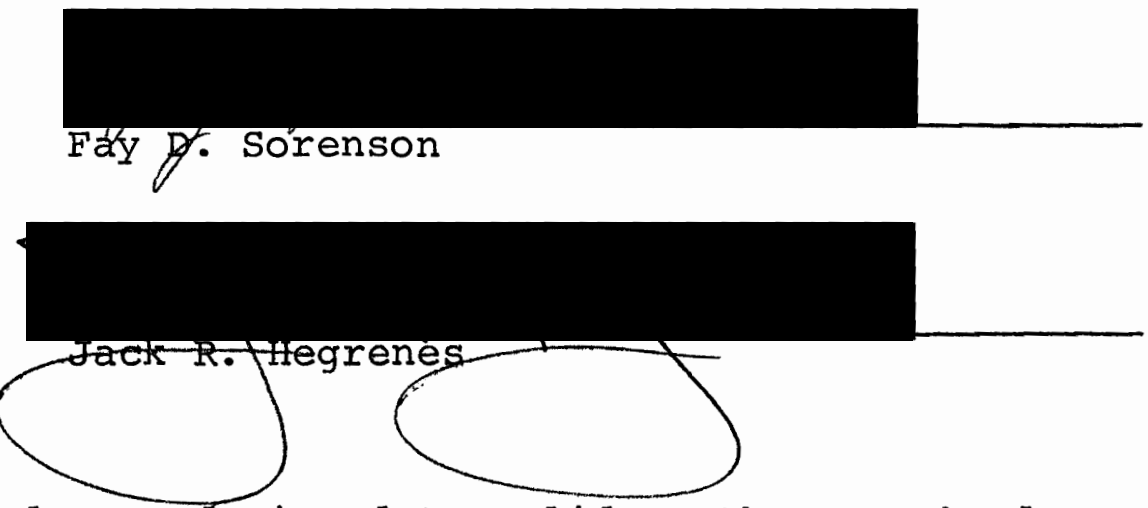

This study was designed to validate the Preschool

Speech and Language Screening Test. The PSIST was designed to quickly identify those preschool children who appear to be in need of speech and/or language evaluation or intervention. Specifically, the present investigation sought to determine the proportion of children with speech and/or language problems not detected by the screening test and the proportion of children without speech and language 
problems who failed the PSLST.

The subjects of this investigation were sixty-eight preschool children in the Portland Public Schools. They were randomly selected from a group of children who were screened in the Fall of 1974. This investigator received the names of the subjects in a random order with no knowledge of whether the subject had passed or failed the screening test.

Two well known tests were used to evaluate the articulation and language of the subjects: the Photo Articulation Test (Pendergast et al., 1965) and the Utah Test of Language Development (Mecham et al., 1969).

Results of the tests used in the validity study were compared with results of the screening test. Analyses showed the language subtests of the PSLST produced 9 false negatives or 13 percent of those tested passed the screening test but failed the validity test. Two false positives or three percent of the subjects failed the language subtests of the PSLST and passed the validity test. On the articulation subtest three false negatives or four percent of those tested passed the screening test but failed the validity test. One false positive or two percent of the subjects failed the articulation subtest of the PSIST and passed the validity test.

The language subtests had too large a proportion of 
false negatives to be considered a valid screening test of language abilities. It did not appear to test many of the language skills necessary for academic success that were tested on the UTLD, such as: auditory and visual memory; eye-hand coordination; and the ability to copy figures and follow directions. These skills are thought by the present investigator to be an important part of language screening. The articulation subtest, however, did effectively identify those children in need of further articulation testing and possibly intervention.

This study was undertaken to determine the validity of the PSLST. The articulation subtest was found to be a fairly valid predictor of articulation ability. This investigator, however, found that the language subtests did not successfully identify children with language problems. Modifications were recommended which would increase the competence of the subtests in locating children with speech and/or language problems. 


\section{VAIIDATION OF THE PRESCHOOL SPEECH AND IANGUAGE SCREENING TEST}

by

SUSAN JANE PACKOUZ

A thesis submitted in partial fulfillment of the requirements for the degree of

MASTER OF SCIENCE IN SPEECH COMMUNICATION:

EMPHASIS SPEECH PATHOLOGY AND AUDIOLOGY

Portland State University

1975 
TO THE OFEICE OF GRADUATE STUDIES AND RESEARCH:

The members of the Committee approve the thesis of Susan Jane Packouz presented May 29, 1975.
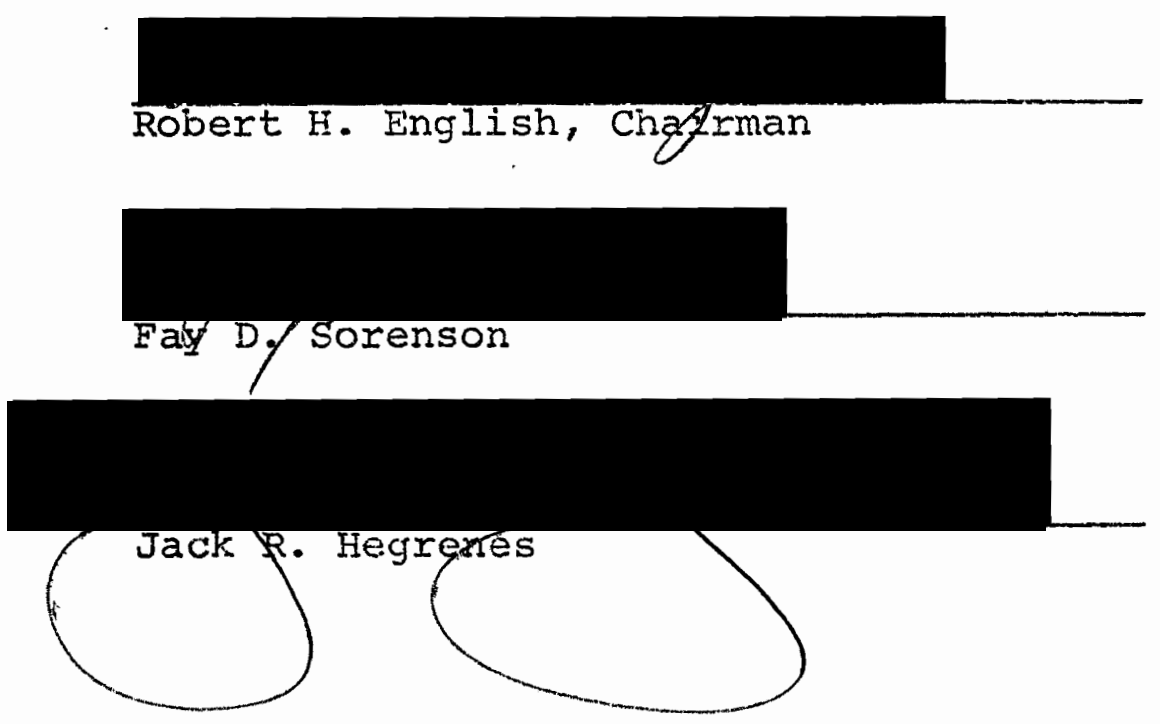

APPROVED :

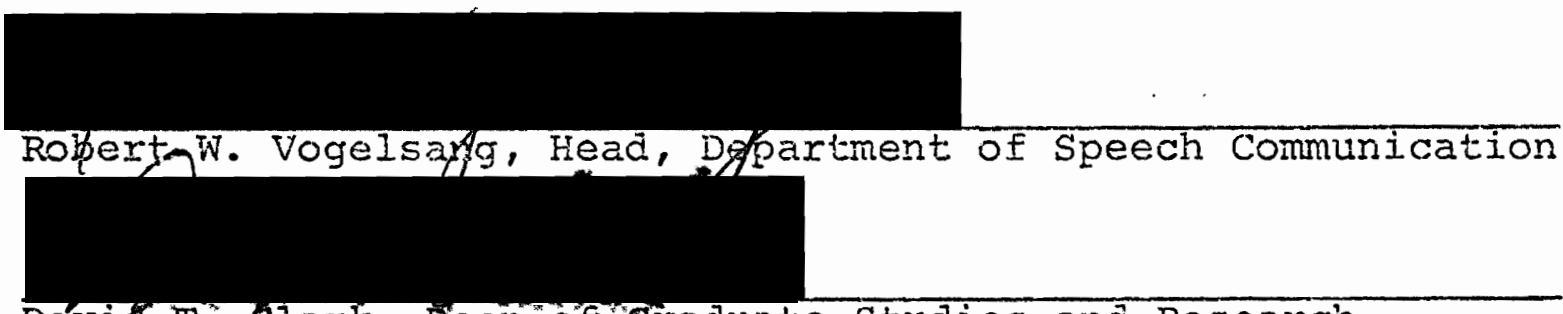

David T. Claxk, Dean of Graduate Studies and Research

June 9,1975 


\section{ACKNOWLEDGMENTS}

I wish to extend my appreciation to the members of my thesis committee, Dr. Robert H. English, Dr. Fay D. Sorenson and Dr. Jack R. Hegrenes. Their comments, suggestions and support were essential to the completion of this thesis. My deepest gratitude goes to Dr. Robert H. English for his understanding and many extra hours of work to help me meet. my deadines.

In addition, I thank the Portland Public School system, particularly Ruth M. Peets, Susan Honson and Eunice Madsen for their help in securing subjects for my study. I am grateful to the parents and children with whom I worked for their cooperation and enthusiasm. They made the collection of data a pleasure.

Finally, my thanks and love to my husband, Ron, for his patience, understanding and love during many late nights of typing, writing and studying. 
TABLE OF CONTENTS

FAGE

ACKNOWLEDGMENTS

iii

IIST OF TABLES. . . . . . . . . . . . . . vi vi

CHAPTER

I INTRODUCTION AND STATEMENT OF THE PROBLEM. • • 1

Introduction. . . . . . . . . . . I

Statement of the Problem. . . . . . . 3

Specific Questions to Be Answered . . . . 4

II REVIEW OF THE IITERATURE . . . . . . . . 5

Background to Speech and Ianguage Screening 5

Articulation Screening. . . . . . . . 9

Screening Tests. . . . . . . . . 9

Diagnostic Testing ......... 13

Language Screening. . . . . . . . . 14

III METHODS AND PROCEDURES . . . . . . . . 19

subjects. . . . . . . . . . 19

Testing Environment......... 20

Methods . . . . . . . . . . 21

Instruments ............. 21

Preschool Speech and Language Screening

Test. . . . . . . . . . 21

Utah Test of Language Development. . . 24 
PAGE

Photo Articulation Test . . . . . . 25

Data Analysis. . . . . . . . . . . 26

IV RESUITS AND DISCUSSION OF RESUITS • • • • • • 28

Results. . . . . . . . . . . . 28

Results from the Language Testing . . 29

Results from the Articulation Testing . $\quad 30$

Specific Items Missed on the UTLD . . $\quad 32$

Discussion of Results. . . . . . . . 34

Language Results. . . . . . . . 34

Articulation Results. . . . . . . 39

V SUMMARY, IMPIICATIONS AND CONCLUSIONS • • . . 42

Summary. . . . . . . . . . . . : 42

Implications . . . . . . . . . . . 44

Future Application. . . . . . . . 44

Future Research . . . . . . . . 45

Conclusion . . . . . . . . . . . 45

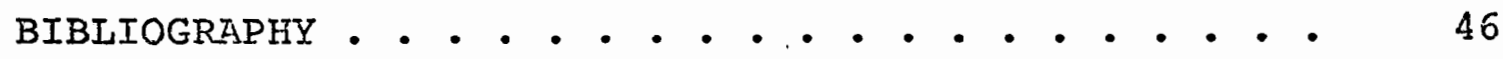

APPENDICES • . • . • . . . . . . . . . . . . . 52

A Pernission Request . . . . . . . . . . 53

B The Preschool speech and Ianguage screening

Test. . . . . . . . . . . . 54

C Utah Test of Language Development. . . . . . 58

D Photo Articulation Test. . . . . . . . 61

E Results and Discussion of the Fall and

Winter Administration of the PSLST. . . 


\section{IIST OE TABLES}

TABLE

PAGE

I Cut-Off Scores of the PSIST . . . . . . . . 23

II Language Test Results . . . . . . . . . . 29

III Articulation Test Results . . . . . . . . . 31

IV Analysis Items Missed by Nine Subjects on the

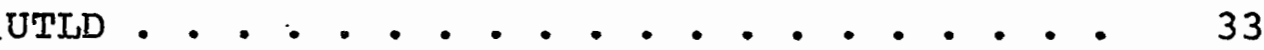




\section{CHAPTER I}

\section{INTRODUCTION AND STATEMENT OF THE PROBIEM}

\section{INTRODUCTION}

Early identification of speech and language problems is important both in the swift and early remediation of such problems and in the prevention of future learning difficulties (Fearon, 1967; Johnson et al., 1967). This identification is the responsibility of the speech clinician.

The two most reliable choices available to the clinician in attempting identification of communicative disorders are: 1) the screening or survey approach; and 2) teacher referrals (Johnson et al., 1967). The screening or survey approach consists of using an instrument which can be adninistered quickly and easily, in order to identify those who have speech and language problems fron those who do not (sommers, 1969). The second alternative, teacher referrals, consists of the clinician asking the teachers and other personnel to refer children they believe have some type of speech and/or language problem.

Eoth approaches have some drawbacks. The teacher referral method has been studied and found to be an inefficient method for the identification of speech and language 
problems. Teachers can be expected to miss two out of every five chilären with defective speech (Diehl and stinnett, 1959).

The major disadvantage of the screening approach has been the lack of short, reliable, standardized language tests. Time has been an especially crucial element in large scale screening of school populations. Children with problems must be located quickly in order to allow sufficient time to institute intervention programs. Many clinicians have had to select a few items from varjous tests and make up their own homemade screening devices which they hoped would reveal possible speech and/or language problems (Irwin, 1965). While these may have been useful in the past, they are clearly not as reliable or efficient as a screening test that has been standardized and validated.

An attempt to solve this problem has been made by Fluharty (1974), who has developed a screening test which measures both expressive and receptive language inclusive of articulation. The Preschool Speech and Language Screening Test (PSIST) was designed to be used with children from two to six years of age. It neasures vocabulary, articulation, comprehension and repetition. The major advantage of this particular test for use with public school populations is that it requires only six minutes to administer. Flunarty compared the pSIST with the Peabody Picture 
Vocabulary Test, the Goldman-Fristoe Test of Articulation and the Northwestern Syntax Screening Test and used these results to determine her cut-off scores on the PSIST. She then used these same tests as a measure of validity. A Pearson product-moment correlation revealed a correlation coefficient of .87 with all three of the above measures. By using the same measures for determining both her cut-off scores as well as determining validity, however, it appears this might have resulted in some degree of cortamination. Hence, to the present investigator, this does not appear to constitute a valid measure of the effectiveness of this test. No further studies have been conducted utilizing different instruments for comparison. Thus, the valiaity of this test has not been fully determinea.

STATEMENT. OF THE PROBLEM

Hence, the purpose of the present investigation was to further determine the validity of the Preschool speech and Ianguage Screening Test as an effective screening device for the identification of children between the ages of two and six years of age who have speech and/or language. problems. Specifically, the PSLST was compared to the Utah Test of Language Deveiopment and the photo Articulation Test, both of which are generally recognized as valid. measures of language and articulation abilities. 
SPECIFIC QUESTIONS TO BE ANSWERED

The four specific questions this investigation sought to answer are:

1. What proportion of subjects tested will be false positives; that is, how many children without a language delay will fail the language portion of the PSLST?

2. What proportion of subjects tested will be false positives; that is, how many children without articulation errors will fail the articulation portion of: the PSIST?

3. What proportion of subjects tested will be false negatives; that is, how many children with a known language delay will pass the language portion of the PSLST?

4. What proportion of subjects tested will be false negatives; that is, how many children with known articulation exrors will pass the articulation portion of the PSIST? 


\section{CHAPTER II}

\section{REVIEW OF THE I.ITERAIURE}

The screening or survey approach is a procedure used to evaluate a large population of children to determine those who have speech and/or language problems. These children would then be referred for further diagnostic testing and possibly speech intervention.

The present review of the literature relative to the process of screening will be presented under three subtopical headings: Background to speech and Ianguage Screening; Articulation Screening; and Language Screening.

\section{BACKGROUND TO SPEECH AND LANGUAGE SCREENING}

Historically, Johnson (1948) discusses three methods for the identification of speech problems. These are class visitations, referrals and the survey approach. Class visitations consist of having the clinician visit each classroom and listen to oral activities. Referrals may be provided by teachers, principals and/or parents. Johnson states the survey approach, however, is probably the most thorough way of locating children with problems of speech, language and hearing. It is a technique which is seen as a quick test of spontaneous and directed speech administered 
individually.

Suydam (1948) conducted a study to determine the type of identification methods used in the public schools. Four principal methods were used, these were: the referral method, consisting of referrals made by teachers, principals and parents; the speech survey method; a combination of the referral and survey methods; and the voluntary enroliment method, in which the child asked for speech help. Questionnaires were sent out to schools in the Middle West. Seventyfive percent indicated they used the speech survey alone or in combination with teacher referrals. Approximately twentyfour percent used teacher referrals alone, while the remaining clinicians indicated they had no systematic method for locating students with speech problems. Three general types of speech surveys were used. These were the questionnaire type, personal interview and a combination of the two. Sixty percent stated they used the personal interview type, with their own "common sense" or judgment as their criteria for success or failure. Suydam felt that rating each child according to a set cut-off score would make these interviews more helpful and valid. This cut-off score would allow the clinician to judge whether a child had passed or failed the screening.

Ainsworth (1948) comments on both the teacher referral and survey methods by stating the survey approach is the most satisfactory way to identify children with speech 
and/or language problems. In his initial survey he suggests asking the child his name, age, grade, any other pertinent information and eliciting a short sample of spontaneous speech. These same alternatives have been stated more recently by Black (1964), Irwin (1965) and Rieber and Brubaker (1966).

The use of teacher referrals has been studied and shown to be ineffective. For example, Diehl and stinnett (1956), in studying the teacher referral method, state elementary teachers can be expected to locate speech defective chilären with less than sixty percent accuracy and will fail to identify two of every five children located by the speech clinician. They found that these same teachers, however, can be expected to locate severe type articulation defectives with eighty percent accuracy or slightly better. Prahl (1964) also found teachers identified more accurately those children who had defects of greater severity.

Some general considerations necessary in screening must be considered. Roe et al. (1961) report eighty-five percert of a sample of 705 clinicians spend one to three weeks in speech screening and ten percent take more than four weeks to screen their schools. These findings emphasize the first important consideration in a screening test, the economy of time. Fearon (1967) also points out that screening is a long task for the clinician. Black (1964) states that hundreds of children must be screened, so the 
process should be rapid but still allow for a high degree of accuracy.

Task Force Reports (1972) emphasize three important objectives in screening. These include: quickness; passfail accuracy; and a precise statement of the goal to be accomplished by the screening. The reliability and validity of rapid screening procedures also should be tested regularly, hopefully yielding false positive and false negative rates of less than one percent (Hamilton, 1974).

Wright and Levin (1971) summarize the foregoing considerations in a statement of objectives for the use of preschool speech and language screening tests.

Objectives: A standardized preschool screening test should meet the following conditions:

1. It should differentiate between children who have an articulation and/or language disorder, and those whose articulation and language development are within the normal range.

2. It should assess language, vocabulary and articulation separately.

3. It should show the relationship among language, vocabulary and articulation.

4. It should be short and interesting to the child. Disinterest and fatigue should be minimized.

5. It should be free of cultural and regional differences in dialect and grammar.

6. Results should be comnunicated in such a way that effective and appropriate follow-up will be facilitated.

Thus, in summary, a few of the considerations of a speech and language screening test should include: speed or 
economy of time; accuracy and ease of administration; and applicability of results to remediation.

\section{ARTICULATION SCREENING}

Articulation testing is the process of judging a person's production of the sounds of a language. There are two major ways of measuring or studying articulation ability. these are: 1) the screening articulation test; and 2) the diagnostic articulation test.

\section{Screening Tests}

Articulation screening is one way of judging a child's articulation abilities. Unlike a diagnostic test, it does not examine all sounds. It should, however, enable the clinician to obtain a representative sample of a child's sound production in order to judge articulatory proficiency. A screening test should be used to locate those children who would benefit from speech intervention (Templin, 1953). Most importantly, it should be short enough to use in large scale situations.

Sanders (1971) states a screening test should select children in need of further diagnostic testing. It should help to rule out articulation disorders in children who have been referred for other speech and language problems such as stuttering or voice disorders. The test should be short but include a good sample of consonants and vowels. 
Winitz (1969) defines a screening test as one which allows for a comparison between a child's articulatory performance and that of his peers. In order to do this, a total articulation score is determined which can be compared with a cut-off score. This cut-off score should be determined in advance, thus, allowing. the clinician to separaite adequate from inadequate performance. According to Winitz, the only function of this sort of soreening test is to compare a child's articulatory score with that of his peers. He further warns that screening tests of this type are of limited value. First, many children have a single, consistent error which may require intensive instruction. It would be unreasonable to select a child for articulatory instruction on the basis of his "total" sound errors. Second, it also is unreasonable to select a child for instruction when he may improve without speech correction. Winitz summarizes by stating that a statistical cut-off score is only one of the criteria that should be used in a screening test. A few others are: level of developmental achievement of phoneme contrasts; parental concern, if displayed; level of articulatory performance needed in school; and a knowledge of whether the sound will be corrected spontaneously by the child.

Perkins (1971) states that screening tests are used extensively in the public schools to locate children with defective speech. They are utilized when a quick decision 
is needed about the general adequacy of articulation. Due to time limitations, they are necessarily gross in the abilities they test. Thus, their major advantage is in separating those who need further testing from those who do not. Quite often these tests are constructed by the clinician to meet specific local needs.

Articulation screening devices can be informal, formal or modifications of diagnostic tests. Informal devices are described by Sanders (1972) and can consist of at least two procedures: 1) spontaneous speech, i.e., the child is asked to talk about or name several objects or pictures; or 2) reading structured sentences, i.e., the child is requested to read several sentences which contain frequently misarticulated sounds. One common method of informal. testing is to ask the child his name, age, address, count to ten and name the days of the week or the months of the year. These informal tests have no criteria other than the clinician's own judgment with which to judge articulatory proficiency.

More formal articulation testing devices are represented by a test developed by Bryngelson and Glaspey (1962). This test is included in a kit titled speech in the classroom and it also includes a set of speech improvement cards. The test itself is composed of sixteen cards used to test sixteen sounds in particular positions in words. (i.e., initial, medial and final). Sanders (1972) feels it pro- 
vides a group of sounds that are more commonly misarticulated by children.

The Denver Articulation Screening Exam (Drumwright et al., 1973) was designed to be used with children from economically disadvantaged backgrounds. It attempts to discriminate between normal variations in the acquisition of speech sounds and developmental delay. It also was designed to detect deviations related to tongue thrusting, lateral lisping and the hypo or hypernasal voice. The authors state it was not intended to be diagnostic; it is simple to use and can be scored accurately by those who are not speech clinicians.

The Templin-Darley Screening Test (Templin and Darley, $1969)$ is one of several tests that have been modified from a longer diagnostic device. It consists of fifty items which are felt by the authors to discriminate between good and poor articulation in preschool and kindergarten children. Validity was demonstrated by comparing the fifty item test with listener judgments. This resulted in a correlation coefficient of .92. Nichols (1966) estimates that an average of two and a half minutes are spent using the screening test. He feels it is the best procedure for screening articulation.

Sanders (1972) disagrees with the statements of Nichols (1966). She reports that the Templin-Darley Screening Test is not comprehensive enough to be used as 
a diagnostic test and too long to be used as a screening device.

The Fisher-Iogemann Test of Articulation Competence (Fisher and Logemann, 1971) represents another diagnostic test which can be modified to use as a screening device. It tests the age levels from young children through adults. The complete form takes twenty-five minutes and the screening form takes ten minutes. Differing from other articulation tests, it aims to show the nature of phonemic accuracy and the commonalities between each phoneme in error. The articulation errors are then summarized according to a distinctive feature analysis, with consonants judged according to voicing, place and manner of articulation; and the vowels according to the height of the tongue, place of articulation, degree of tension and lip rounding. No norms have been established, thus, a numerical score is not available. This feature makes it difficult to use the test in a screening situation which requires quick scoring.

Diagnostj.c Testing

The second major way of measuring articulation ability is the use of the diagnostic test. Darley (1964) states a diagnostic test is used if a detailed description and analysis of articulation is desired. Sanders (1972) elaborates by adding it should include all consonants and vowels and should allow the clinician to judge the 
- . number of sounds misarticulated, the developmental level of the sounds, the position of the error sound in the word, the type of error sound and the frequency of occurrence of the sound misarticulated.

This kind of detailed analysis is important when speciric information is needed to initiate management procedures. Due to its length, however, a diagnostic test would not be practical when testing several hundred children in a public school situation.

\section{LANGUAGE SCREENING}

According to Nichols (1966), prior to 1966 no valid, reliable or economical procedures existed to screen children for possible language deficits. In fact, this investigator has found reither prior to nor since 1966 have there been many tests for language competency which fit the criteria of a screening test for use in assessing large groups of children.

It is to be noted, however, that several tests have appeared which may be considered as possible screening tests. One of the first such tests to appear was the Northwestern Syntax Scxeening Test by Lee (1971). It tests the age ranges from three to eight years of age in an average of fifteen minutes per child. Designed to measure the expressive and receptive use of the syntactical elements of language, it includes such grammatical elements as 
prepositions, personal pronouns, negatives, plurals, verb tenses, possessives, wh-questions and yes-no questions. Sanders (1972) suggests it may be desirable to modify the test by discontinuing if the child misses the first ten items or if he performs successfully on enough items to reach a score comparable to the tenth percentile for his age level. This would help to shorten the test and make it more useful as a screening device. This, however, precludes the use of the norms.

The Utah Test of Language Development has been adapted by its authors, Mecham et al. (1973) for use as a screening device by using five test items. These items take approximately two and a half minutes to administer. When compared with the full scale Language Age Equivalent scores for 163 children, the combination of the five items was in one hundred percent agreement. The authors feel this short version should be used as a mass screening test with the full test utilized for rechecking those screened out by the short test.

Several other tests have been developed recently which can most accurately be designated as combined language tests. Some of them include language, articulation and various other dimensions of speech such as voice or fluency. Monsees and Berman (1968) designed a speech and language screening test which includes articulation, vocabulary and expressive language tasks. It takes approximately 
five minutes to administer and was designed to be used with predominately black populations. Each child is asked to state his name, age, identify body parts, follow directions and compose a story about some pictures. No studies of reliability or validity, as yet, have been conducted.

Developed for use as an "evaluation instrument," the Preschool Eanguage Scale (zimmerman et al., 1969) provides for the examination of children ranging in age from one year, six months to seven years. Its purpose is to diagnose and isolate strengths and weaknesses in language skills, such as: grammar; number concepts; memory; body parts; time-space; and logical thinking. The scale is divided into two sections, the Auditory Comprehension scale and the Verbal Ability Scale. The Verbal Ability Scale also includes an articulation section. The PLS takes approximately thirty minutes to administer, and has been standardized on 174 Head start children from a middle-size, ruralurban center.

The Preschool Language Screening Test (Hannah and Gardner, 1974) was designed to identify children with a language deficit who need further diagnostic evaluation. It tests the functioning of the auditory, visual, and motor channels and includes a brief measure of conceptual development. Testing the age range of $2-6$ to $6-0$, it takes from twenty-five to thirty-five minutes to administer. The PLST was standardized on 180 children between the ages of $3-0$ and 
5-6 years who lived in the San Fernando Valley area of Los Angeles. Ninety of the children were from white, middle class nursery schools or kindergartens, and ninety were from Headstart and day care centers. Percentiles are available for each section of the test, and normative data is provided for both groups of children. Test-retest reliability revealed a correlation of .95 . When compared with the results of the Illinois Test of Psycholinguistic Abilities (Kirk et al., 1968) the PLST appeared to distinguish those in need of further diagnostic evaluation.

The Preschool Articulation and Language Screening Test (Wright and Levin, 1971) is still another recently developed test which combines articulation and expressive language. It takes approximately five to seven minutes to administer. The authors assume that receptive language abilities develop first, and, thus, will be revealed in the expressive language abilities that are measured. A validation study was done on 152 black children from 2-6 to 5-6 years of age. Validity was shown by a comparison with the Templin-Darley Test of Articulation and the Peabody Picture Vocabulary Test. Correlation coefficients of .608 to .869 were obtained when compared with the Templin-Darley and .356 to .595 when compared with the Peabody.

Measuring language, articulation, voice and fluency, the Oregon School Entxance Speech Screening Test (OSESST) was developed as part of a three hour Modular Health 
Examination (Anderson, 1972). Designed to be used with first grade children, it can be administered in four to seven minutes. A validation study was done by Hamilton (1974) utilizing the Utah Test of Language Development, the Photo Articulation Test, the Northwestern Syntax Screening Test, the Jewish Hospital Voice Profile, Bioodstain's Developmental Phases of Stuttering and Riley's Stuttering Severity Instrument in order to check the validity of the OSESST. The voice and fluency subtests were found to be valid measures. The investigator, however, felt changes were needed in the articulation and language subtests, since more than one percent of the children tested were not correctly identified with the OSESST.

It has been noted in the foregoing review of the literature that there is a definite need for screening tests that measure various dimensions of speech and language. More specifically, screening tests that are not only fast, but reliable, valid and standardized measures with efficient cut-off scores. Hence, the present study was designed in effect to help determine the validity of the PSLST. Specifically, does this particular screening test identify effectively those preschool children who need speech and/or language intervention? 


\section{METHODS AND PROCEDURES}

The following is a discussion of the methods and procedures utilized in the present study. Specifically, the selection of subjects, the testing environment, the methods used, the instruments utilized for testing as well as the analysis of data will be presented.

\section{SUBJECTS}

The subjects for this study were chosen from children who took part in the Portland Public Schools Kindergarten screening program in the Fall of 1974. Seven schools in Southeast Portland were screened by this examiner and four othe clinicians utilizing the PSLST. From this pool of 280 children, one hundred were selected by a random sampling procedure; eighty to act as subjects for this study and twenty to be used as aiternates should any of the first eighty be unable to participate in the investigation. A list of eighty names was then given to the examiner. The exarniner did not know which chilaren had passed or which had failed the screening test administered in the Fall of 1974.

Due to the large number of children who moved out of 
the district and several parents who refused to allow their children to participate, it was necessary to resort to the use of the twenty alternates. From the group of alternates there were also several who had moved and a few whose parents refused permission; hence, the final total of children utilized in this study was sixty-eight, 31 were boys and 37 were girls ranging in age from 5 to 6 years. No attempt was made to test further children due to time limitations.

For the purpose of the present investigation a preschool population was defined as those children who range in age from four years through the six year level. No attempts were made to control for intelligence, socioeconomic level or sex, since the purpose was not to compare groups but to compare each individual's performance separately.

\section{TESTING ENVIRONMENT}

Retesting took place during the months of February and March of 1975. Each child was seen individually for between forty and fifty minutes. After an initial introduction to the principal of each school, all further arrangements were made with the respective kindergarten teachers. It was necessary to make separate arrangements in each school, but most often a small, separate room was provided. These were generally very quiet and conducive to testing. In the remaining cases it was necessary to work from a 
table in the hall. This proved to be a sometimes distracting but adequate testing setting:

\section{METHODS}

Parental permission slips were sent home with each prospective subject (refer to Appendix A). When the approved slip was returned each subject was retested with the Utah Test of Language Development, the Photo Articulation Test and a second PSLST.

The order of presentation for the three tests was done randomly. Each child was told he would be looking at some pictures; hence, each appeared to approach the testing situation as though it were a game. Standardized instructions were given at the beginning of each new test, following the directions in each test manual. Reinforcement in the form of social praise was used throughout the sessions.

INSTRUMENTS

The instruments utilized in the present investigation were the Preschool Speech and Language Screening Test, the Utah Test of Language Development and the Photo Articulaticn Test. Each test is described in detail below.

Preschool Speech and Language Screening Test

The PSLST was designed for use with children from two 
to six years of age, and uses thirty-five questions to test both expressive and receptive language abilities (see Appendix $B$ for a copy of the test form). It takes an average of six minutes to administer. The first of three parts, section A, seeks to measure both vocabulary and articulation ability. Fifteen objects are presented and the child is scored on correct identification as well as articulatory proficiency. On the articulation portion, twenty-three phonemes are tested utilizing Sander's (1972) data. He feels these phonemes reach "customary production" by the preschool years. The objects chosen to measure both vocabulary and articulation were chosen from the first 1500 words of the Thorndike list, as listed in Better Speech and Better Reading (Schoolfield, 1951). A total score of thirty is possible on the articulation section and fifteen on the vocabulary section. These total scores can then be compared with the cut-off scores provided to determine whether the child has passed or failed each section (refer to Table I). Cut-off scores are now available for the ages two through six years in the four areas of identification, articulation, expressive language and receptive language.

These cut-off sccres were derived from tests frequently used with preschool children, such as: the Peabody Picture Vocabulary Test (Dunn, 1959); the Goldman-Fristoe Test of Articulation (Goldman and Fristoe, 1969); and the Northwestern Syntax Screening Test (Lee, 1969). These same 
tests were used to determine the validity of the PSLST as previously mentioned.

TABLE I

CUT-OFF SCORES FOR THE PSIST

Ages Identification Articulation Comprehension Repetition Total Total Total Total

\begin{tabular}{lrlll}
\hline 2 years & 9 & 18 & 4 & 3 \\
3 years & 11 & 19 & 6 & 4 \\
4 years & 12 & 21 & 7 & 6 \\
5 years & 13 & 25 & 8 & 7 \\
6 years & 14 & 26 & 8 & 8 \\
\hline
\end{tabular}

Section B provides an estimate of the child's receptive language abilities. According to Fluharty (1974), it requires non-verbal responses to sentences incorporating ten basic syntactical structures. These include five basic kernel sentences and five transformations expected during the preschool years. Section B utilizes the objects from Section $A$ for eight of the ten sentences. The words used in the remaining two sentences also were chosen from the first 1500 words on the Thorndike Iist.

Section $C$ allows for the evaluation of the child's expressive language and consists of having the child imitate one sentence descriptions of ten photographs. The 
use of imitation as a measure of expressive language has been confirmed by a number of authors (McNeill, 1966; ErvinTripp, 1964; Menyuk, 1971; and Shipley, Smith and Gleitman, 1965).

The rationale underlying this test is based on a psycholinguistic description of language. Appropriate selection of items was based on developmental studies of both articulation and language. The PSLST was standardized on 203 children between the ages of three and five.

\section{Utah Test of Language Development}

This test is commonly referred to as the UTLD (Mecham et al., 1969, 1973) and it purports to evaluate both expressive and receptive language. A revision of the Verbal Language Development Scale, it utilizes the developmental approach for the appraisal of language (refer to Appendix C for a copy of the test form). There are fifty-one items testing the age range from 1.5 through 14.5 years. Forty percent of the items test ages one through four, thirtyfive percent test ages five through nine, and sixteen percent test ages ten through fifteen. The estimated administration time of the UTLD is between twenty and thirty minutes. This test was useful in this study because, as Butler (1972) states: "The UTLD is particularly useful at the preschool level due to the preponderance of items at the level and the absence of time limits." 
Standardized on 273 normal, white children in a portion of Utah, the reliability coefficient was .94 utilizing the split-half method. The authors feel the test has good face validity because all items have been selected fxom standardized sources. The language items were chosen from such sources as: the Stanford-Binet; Gesell Developmental Schedules; Vineland Social Maturity Scale; Peabody Picture Vocabulary Test; and Verbal Language Development Scale. In using the UTLD, testing is begun at the child's chronological age. If he fails to achieve eight consecutive correct responses, the examiner must test downward until eight consecutive correct answers are achieved. Items are then tested upwards until at least eight consecutive minuses are scored. The total raw score is devised by counting the total correct above the basal score. A language age is determined by looking-up in the manual the total raw score, and noting its corresponding Language Age Equivalent (LAE).

Photo Articulation Test

This test is referred to as the PAT (see Appendix D for a copy of the test form), and has seventy-two photographs used to elicit a sampie of a child's articulatory proficiency for single word responses. Each photograph elicits one consonant and sometimes one vowel or diphthong. All consonant sounds are tested in the initial, medial and 
final positions of words. The PAT was developed in 1960 and takes five minutes, on the average, to administer. It was standardized on 3,000 elementary school children from the Seattle, Washington, area.

The Bryngelson and Glaspey kit, Speech in the Classroom and the Templin-Darley Screening Test of Articulation were both used to validate the PAT. Correlations of .984 and .975 respectively were reported. Test-retest reliability was .991. The authors (Pendergast, Dickey, Selmar and Soder, 1965) state that the items have been grouped for definite diagnostic purposes.

\section{DATA ANALYSIS}

In the present study, results from the identification, comprehension and repetition subtests of the PSLST were examined as a single unit and compared with the results of the Utah Test of Language Development. The articulation subtest scores were compared with the results from the Photo Articulation Test.

Following the criteria established by the Hamilton study (1974), failure on the UTID is a language age score ten months or more below the subject's chronological age. As recommended by Sanders (1972), Templin's (1957) age norms were applied to each consonant tested with the PAT. The criteria for failing the pAT was determined by three experienced clinicians at Portland State University. This 
was based on clinical judgment as well as several other studies which utilized a similar criterion (Prins, 1962; Jenkins and Lohr, 1964). Failure on the PAT was arbitrarily established as three or more errors on sounds below the age level of the child. These were: 1) misarticulation of a singie sound in the initial, medial or final positions of words; 2) misarticulation of three different sounds in any position of a word; and/or 3) misarticulation of three sounds in any position, two of one sound and one of another sound, etcetera.

Thus, as seen above, each child was judged according to a pass-fail criterion on all three tests. The results and conclusions from these tests are discussed in chapter IV. 
CHAPTER IV

RESULTS AND DISCUSSION OF RESULTS

RESULTS

Results from the Preschool Speech and Language Screening Test administered in the Winter of 1975 were compared with results from the Utah Test of Language Development and the photo Articulation Test. Additionaliy, the results of the PSLST administered in the Fall of 1974 were compared with those from the PSIST administered to the same children in the Winter of 1975 in order to determine if this instrument could show growth in a child's abilities over time. Although the latter was not a part of the originally stated purpose of the present study, this investigator felt such information not only might be of interest but of further value in describing the PSLST as a screening device for use in settings where large groups of children need to be processed rapidly. Tables were generated to numerically describe and compare the collective data from these instruments. These results can be found in Appendix $\mathbf{E}$.

These results were compared according to: 1) the number of false negatives, those children with articulation or language problems who were undetected by the PSLST; 2) that 
number of false positives, those children with no articulation or language problems but who were failed by the screening test; and 3) those scores from both testing procedures which were found to be in agreement.

Results from the Ianguage Testing

Displayed in Table II are the results from the language tests. These data are the product of the language subtests

TABIE II

I.ANGUAGE TEST RESULTS

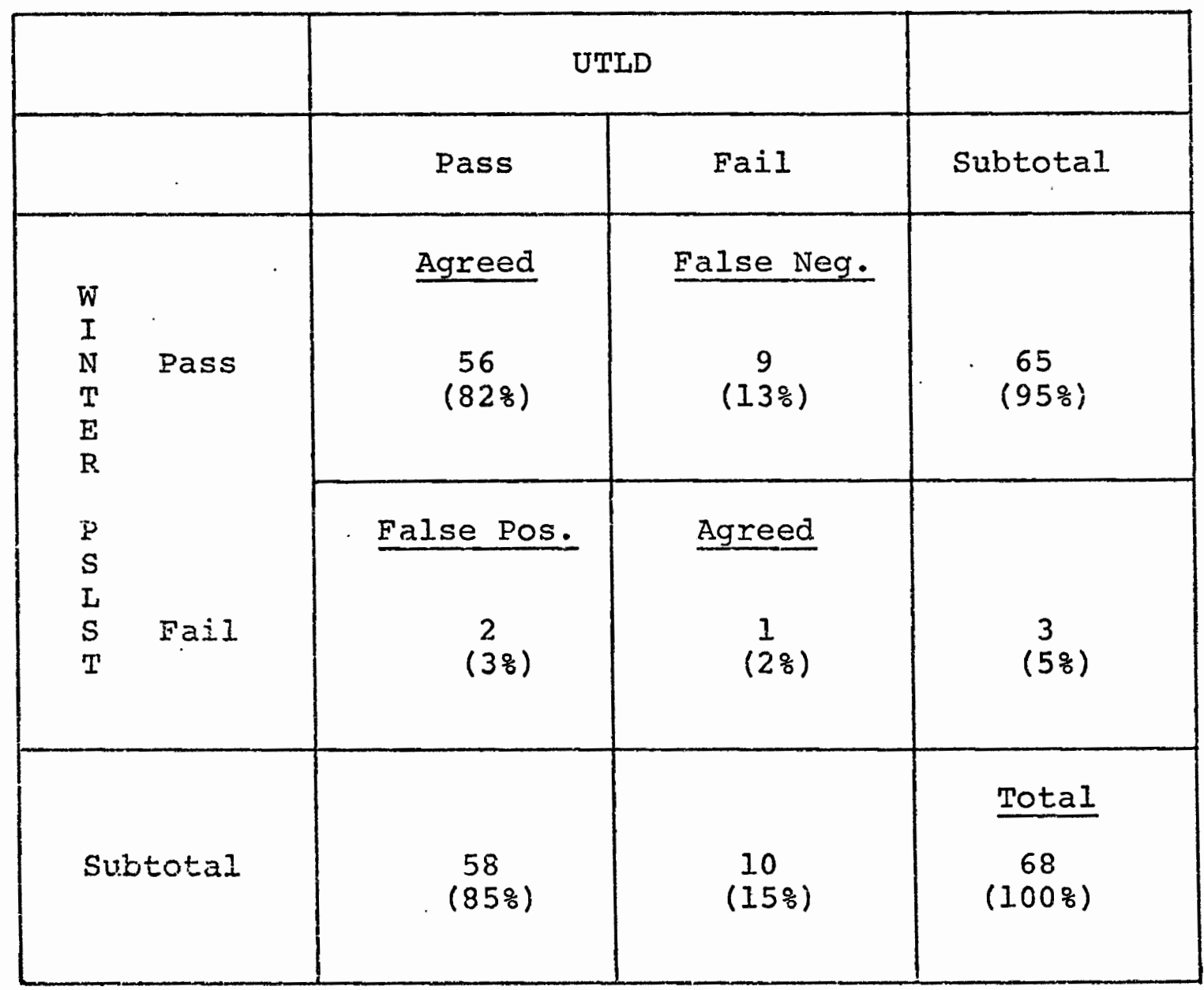


of the PSLST given in the winter of 1975 and the UTLD used in the present study as a validation device. It is to be noted that this table shows the number and percentage of subjects who: 1) passed or failed both tests; 2) failed the screening test and passed the longer language test; and 3) passed the screening test and failed the UTLD.

These results assisted in answering two of the specific questions posed by the present study:

1. What are the estimated false negatives, i.e., what proportion of children with language problems was not detected by the PSLST?

Results: The winter PSIST language subtests produced 9 false negatives or 13 percent of those tested.

2. What are the estimated false positives, i.e., what proportion of children without language problems failed the PSLST?

Results: The PSLST produced 2 false positives or 3 percent of those tested.

As noted above, Table II also reveals the number and percentage of subjects which passed both tests or failed both tests, i.e., those results which are in agreement. The combined results of these tests show 57 or $84 \%$ of the subjects received similar scores on both tests.

Results from the Articulation Testing

Table III displays the results of the articulation subtest of the PSLST given in the winter of 1975 with those of the PAT. Specifically, this table shows the number and 
percentage of subjects who: 1) passed both tests; 2)

failed the screening test and passed the PAT; and 3) passed the screening test and failed the PAT.

Data presented in Table III helped in answering the two remaining questions asked in the current study:

1. What are the estimated false negatives, i.e., what proportion of children with articulation problems was not detected by the PSLST?

Results: The PSLST produced 3 false negatives or 4 percent of those tested.

TABLE III

ARTICULATION TEST RESULTS

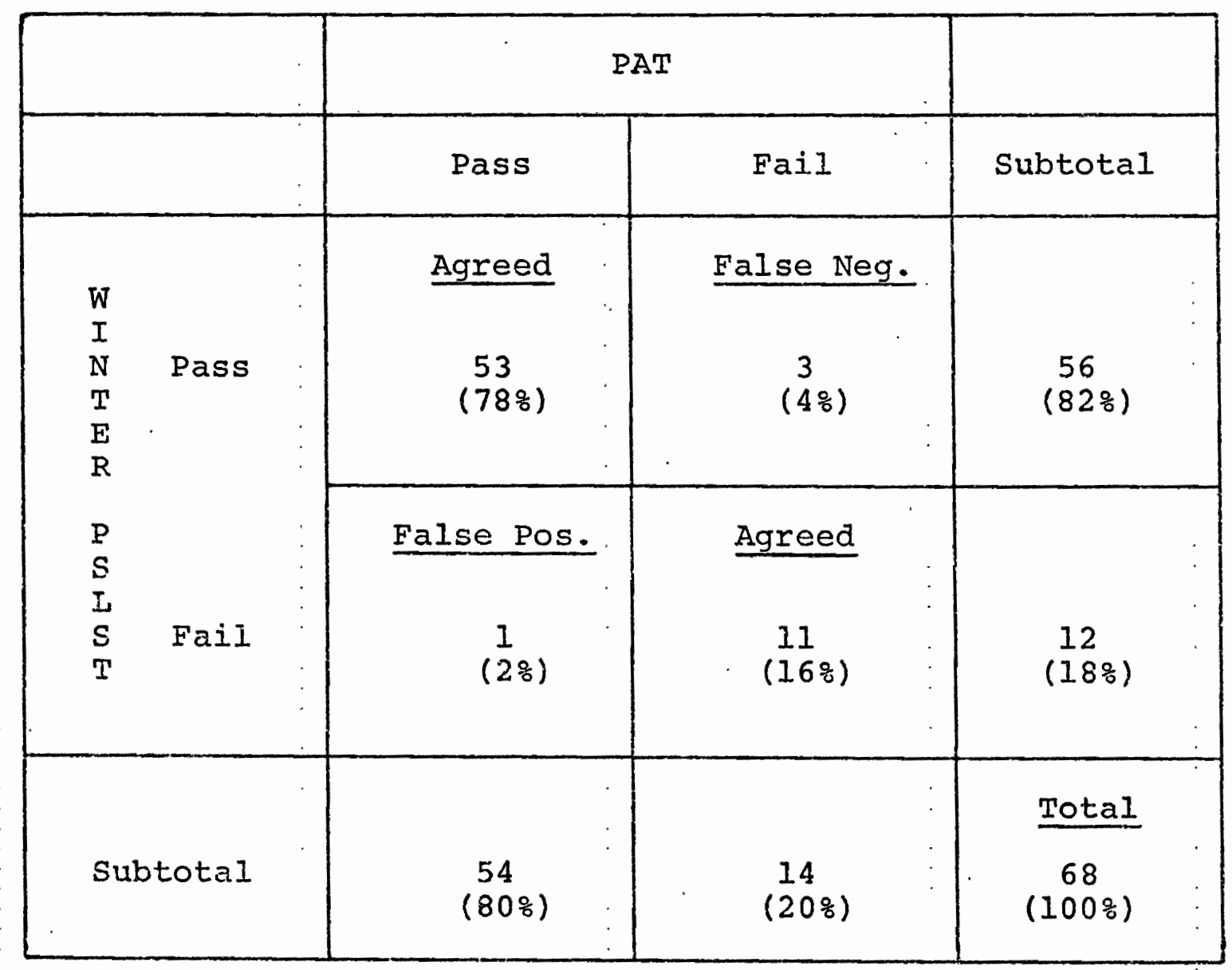


2. What are the estimated false positives, i.e., what proportion of children without articulation problems failed the PSLST?

Results: The PSLST produced I false positive or 2 percent of those tested.

In addition, Table IIJ reveals the number and percentage of subjects who passed and failed both the screening test and the diagnostic test. It shows that 64 or $94 \%$ of the subjects obtained similar scores on both tests.

Specific Items Missed on the UTLD

This investigator became concerned over the fact that 9 subjects out of 68 or 13 percent passed the PSIST, but failed the UTLD as noted in Table II; hence, a simple numerical item analysis was done for items missed on the UTLD. Results of this analysis are presented in Table IV. It is to be recognized that the ideal screening test is one which will screen-out all subjects in need of a thorough diagnostic work-up and/or inclusion in an intervention program. Such a test, however, should not identify an excessive number of children who are not in need of diagnosis and/or intervention. Based on this concept, an arbitrary number of four or one less than half of the nine subjects failing a given item on the UTLD was selected as an arbitrary failure rate.

Using the criterion of four it is to be noted that the nine subjects collectively failed eight out of fourteen of the items tested on the UTLD, which include: Receptive 
TAELE IV

ANAIYSIS OF ITEMS MISSED ON THE UTID BY NINE SUBJECTS PASSED

BY THE PSIST, SHOWING ITEMS SIMILAR ON BOTH TESTS

\begin{tabular}{|c|c|c|c|c|c|c|c|c|c|c|c|c|c|c|}
\hline Leve & & II-III & & & III- & $-I V$ & & & IV- & & & & $V-V I$ & \\
\hline $\begin{array}{l}\text { Sub- } \\
\text { ject }\end{array}$ & $\begin{array}{l}\text { Names } \\
\text { Com. } \\
\text { Picts. * }\end{array}$ & $\begin{array}{l}\text { Ident. } \\
\text { Action } \\
\text { *icts . * }\end{array}$ & $\begin{array}{l}\text { Recep- } \\
\text { tive } \\
\text { Vocab.* }\end{array}$ & $\begin{array}{l}\text { Dhree } \\
\text { Dig- } \\
\text { its }\end{array}$ & $\begin{array}{l}\text { Gives } \\
\text { Full } \\
\text { Name }\end{array}$ & $\begin{array}{l}\text { Repeats } \\
\text { Nursery } \\
\text { Rhyme }\end{array}$ & $\begin{array}{l}\text { Names } \\
\text { Col- } \\
\text { prs* }\end{array}$ & $\begin{array}{l}\text { Four } \\
\text { Dig- } \\
\text { its }\end{array}$ & $\begin{array}{l}\text { Three } \\
\text { nam- } \\
\text { nands }\end{array}$ & $\begin{array}{l}\text { Twelve } \\
\text { Syl1- } \\
\text { sable } \\
\text { Sent. }\end{array}$ & $\begin{array}{l}\text { Draw- } \\
\text { ing }\end{array}$ & $\begin{array}{l}\text { Prints } \\
\text { Name, } \\
\text { etc. }\end{array}$ & $\begin{array}{l}\text { Recep- } \\
\text { tive } \\
\text { Nocab. }\end{array}$ & $\begin{array}{l}\text { Draws } \\
\text { Geo. } \\
\text { Figs. }\end{array}$ \\
\hline$I$ & $\mathrm{X}$ & $\mathrm{X}$ & $\mathrm{X}$ & & & $x$ & & & $\mathrm{X}$ & $X$ & & $\mathrm{X}$ & & $\mathrm{X}$ \\
\hline 2 & . & $\mathrm{X}$ & $\mathrm{X}$ & & & $\mathrm{x}$ & $X$ & & $\mathrm{X}$ & & & $\mathrm{X}$ & $\mathrm{X}$ & $\mathrm{X}$ \\
\hline 3 & & & & & $\mathrm{X}$ & $\mathrm{x}$ & & & & $\mathrm{x}$ & $\mathrm{X}$ & $\mathrm{X}$ & & X \\
\hline 4 & & $\mathrm{X}$ & $\mathrm{X}$ & $\mathrm{X}$ & & & & $\mathrm{X}$ & & & . & $\mathrm{x}$ & & $x$ \\
\hline 5 & & & & & & $X$ & & & $\mathrm{X}$ & & & $\mathrm{X}$ & & ? \\
\hline 6 & & & $X$ & $\mathrm{X}$ & & $\mathrm{X}$ & . & $\mathrm{X}$ & $X$ & $\mathrm{X}$ & & $\mathrm{X}$ & $X$ & $x$ \\
\hline 7 & & & & & & $\mathrm{X}$ & $X$ & $X$ & $\mathrm{X}$ & & & & $\mathrm{X}$ & \\
\hline 8 & & & & & & $\mathrm{X}$ & & & & $\mathrm{X}$ & $\mathrm{X}$ & $\mathrm{X}$ & $\mathrm{X}$ & \\
\hline 9 & & & & $\mathrm{X}$ & & & & $\mathrm{X}$ & & & & $\mathrm{X}$ & $x$ & \\
\hline Total & 1 & 3 & (4) & 3 & 1 & (7) & 2 & (4) & (5) & (4) & 2 & (8) & (5) & (5) \\
\hline
\end{tabular}


Vocabulary (II-III year leveI); Repetition of Four Digits; Following Three Commands; Repetition of a Nursexy Rhyme; Repetition of a Twelve Syliable Sentence; Pxinting; Receptive Vocabulary (V-VI year level); and Drawing Geometric Designs.

\section{DISCUSSION OF RESUISTS}

The language subtests of the PSIST did not prove to be valid predictors of language abilities when compared in the present study with the UTLD. This is shown by the large proportion of false negatives found. The articulation subtest, however, did appear to identify those children in need of further diagnostic evaluation.

\section{Language Results}

The two false positives, those who failed the screening test but passed the diagnostic test (UTLD), both failed the repetition subtest of the PSLST. Six of the seven errors scored by both subjects resulted from the omission of "the" in the beginning of the sentence. This error does not constitute a very serious deficiency in grammar. The remaining error was one of pluralization in which one subject omitted a final "s." The subject correctly used the plural in all other sentences. As stated in Chapter III this subtest was derived from the expressive portion of the Northwestern Syntax Screening Test. Several studies have 
been conducted to support the usage of imitative tasks as measures of expressive language abilities (Ervin-Tripp, 1964; Shipley, Smith and Gleitman, 1965; McNeill, 1.966; and Menyuk, 1971). A recent study by Prutting, Gallagher and Mulac (1975), however, questions the reliability of the NSST as an indicator of expressive language ability. They do not feel specific syntactic structures can be reliably evaluated by such an imitative task and conclude that the expressive portion of the NSST can only be used as a screening device to differentiate clinical populations. They further recommend the usage of a spontaneous language sample to evaluate a child's language abilities. Further research in this area is needed to clearly determine the validity of such tasks.

The false negatives, however, represent the most significant aspect in analyzing the results of the screening test. The language subtests of the PSLST (see Table II above) showed nine or thixteen percent of the sixty-eight subjects tested as false negatives, i.e., those who passed the screening test but failed the diagnostic test. Projecting this to a population of 1000 reveals the screening test could possibly miss 130 children. If this were used in a public school setting too many children who need further diagnosis and/or language intervention would not have been identified. Clearly, this is too large a number and indicates the screening test as now constituted does 
not successfully identify those children with possible language problems. As stated earlier, the ideal test would be one which had false positive and false negative rates of less than one percent. This test obviously exceeded these with false positive rates of three percent and a false negative rate of thirteen percent.

An analysis of the individual test results revealed four of the nine subjects obtained perfect scores on the language subtests of the PSLST, but were from sixteen to twenty-five months below their age level on the language skills as measured by the UTLD. Two of the remaining five subjects showed one language subtest score which was at the cut-off score and both were close to the cut-off score utilized by the UTLD, one at ten months and the other at eleven months below age level. The remaining three subjects had subtest scores on the PSLST within the normal range but showed language age scores from ten to twenty-one months below their chronological ages.

A more detailed analysis of the specific errors obtained by these nine subjects on the UTLD was conducted. Results were presented in Table IV of the preceding section. It was noted a pattern of exrors was shown with four or more of the nine subjects failing the following items on the UTLD: 1) saying a nursery rhyme; 2) following three commands; 3) copying geometric figures; 4) printing two words; 5) repeating four digits; 6) repeating a twelve 
syllable sentence; and 7) receptive vocabulary at both the two through three year level and the five through six year level.

These items are similar in three major dimensions. First, and perhaps most importantly, they all represent what might be termed automatic, abstract or rote memory. Specifically, they appear to test auditory memory, visual memory and/or auditory-visual memory. These are features which are not adequately tapped by the screening test but which are essential in improving and increasing language skills.

Mecham et al. (1973), in their revision of the UTLD into a screening device, utilized four of the above items plus one more to test language abilities. These were:

1) saying a nursery rhyme; 2) naming colors; 3) repeating a twelve syllable sentence; 4) copying a square; and 5) receptive vocabulary at the five to six year level. They found these items were in 100 percent agreement when compared with the longer version of the test. In addition, this longer version of the test has a correlation of .860 with the Illinois Test of Psycholinguistic Abilities (Kirk et al., 19.68) which tests many aspects of language development in depth.

A second dimension common to many of these items is that they all appear to represent skills necessary for academic success. For example, it is very important that 
children have the ability to copy figures and follow directions. These are a part of the foundation for many higher language skills such as reading and writing. Bell (1972), in a home-based guide to preschool education, stresses many of the same skills as important in preparing a child for school. Parents are given suggestions to improve both auditory and visual skills similar to those tested by the UTID. The importance of such items also has been shown by their inclusion in other language screening tests. For example, similar items are included in the speech and language screening test developed by Monsees and Berman (1968). The child must follow directions, compose a story and state his name and age. Still another test previously mentioned, the Preschool Language Screening Test (Hannah and Gardner, 1974), measures auditory and visual skills as well as conceptual development. Such items appear to be recognized as testing important language abilities.

The final dimension seen in these items is that they do not use concrete or manipulable objects to elicit a response. The only exceptions are in the copying of geometric figures in which the child has a model of the desired figure and receptive vocabulary which utilizes pictures. The PSLST, in contrast, uses a concrete object for each item on the test. Items similar to those found in the UTLD also have been included in other language tests discussed eaxlier. These items appear to rely more on memory or abstract 
reasoning than on the presence of a specific object. Among these are the Oregon School Entrance Speech Screening Test (Anderson, 1972) and the screening test designed by Monsees and Berman (1968).

\section{Articuiation Results}

One false positive, who failed the screening test but passed the diagnostic test, was revealed in the articulation portion of this study (see Table III). This subject scored one point below the cut-off score on the PSLST. He misarticulated $/ \theta /, / n /,|t / /| d, z /, \mid f /$ and $/ v /$. on the PAT his errors were on the $/ \theta /, / V /$ and $/ \delta /$ sounds in all positions. Although he did show several errors, they were all sounds that are not expected to be correctly articulated at his age level (Templin, 1957).

Three false negatives; those who passed the screening test but failed the diagnostic test, were obtained on the articulation subtest. The first of these subjects obtained a score that was the same as the cut-off score. He misarticulated the initial and final /s/, / $/$ and $/ \mathrm{v} /$ sounds. On the PAT he misarticulated the /s/ in all positions and the $/ v /$ and $/ z /$ sounds in a single position. If the medial /s/ had been tested with the PSLST it is possible this subject would have failed both the screening and the diagnostic tests. The next subject misarticulated / $/$ / on the PSLST and the $/ x /$ in all three positions on the PAT. The third false negative subject misarticulated the $/ \theta /, / S /$ and $/ 1 /$ 
sounds in one position on the PSLST while on the PAT he misarticulated the $/ S /$ in two positions and the $/ t /|,| \gamma /,|x|$ and the $/ \theta /$ sound in only one position.

These differences between the screening and the diagnostic test show a pattern. First, most of the sounds described above represert those which could be called the more frequently misarticulated sounds at this age level, i.e., $[s, r, 1,5]$. In fact, all of the three sounds, $[s, r, S]$, which could have made a significant difference in the results are represented in this troublesome group. secondly, had these sounds been tested in all three positions by the PSIST it is very likely that each of the three false negative subjects might have failed the screening test as they did the diagnostic test. This may have reduced both the false positive and false negative results and brought them closer to the one percent proposed by Hamilton (1974). Clearly, by testing a few of the sounds such as $/ s /, / I /, / I /$ and $/ S /$ in all positions, it is possible the PSLST could have proven to be a more valid screening test and yet would not have increased the administration time significantly. This method has been applied by Bryngelson and Glaspey (1962) in their screening test of articulation and does not make test administration time excessive. Although the above factors seem to account for the false negatives revealed in the articulation testing, other factors may have influenced the results. These are 
discussed in detail by Winitz (1969). He points out that there may be variance due to the subjects, due to the experimenter, due to the test instrument and/or due to the interaction of the subject with the expeximenter. All of these factors may contribute to differences in an individual child's performance on an articulation test.

As shown by the small number of false negatives (refer to Table III), however, this subtest, as it stands, does prove to successfully identify most of the children with articulation problems. It would appear to be a fairly good predictor of articulatory proficiency. 
CHAPTER V

SUMMARY, IMPLICATIONS AND CONCLUSIONS

\section{SUMMARY}

This study was designed to validate the Preschool

Speech and Language Screening Test. The PSIST was designed to quickly identify those preschool children who appear to be in need of speech and/or language evaluation or intervention. Specifically, the present investigation sought to determine the proportion of children with speech and/or language problems not detected by the screening test and the proportion of children without speech and language problems who failed the PSLST.

The subjects of this investigation were sixty-eight preschool children in the Portland Public Schools. They were randomly selected from a group of children who were screered in the Fall of 1974. This investigator received the names of the subjects in a random order with no knowiedge of whether the subject had passed or failed the screening test.

Two well known tests were used to evaluate the articulation and language of the subjects: the photo Articulation Test (Pendergast et al., 1965) and the Utah Test of 
Language Development (Mecham et al., 1969).

Results of the tests used in the validity study were compared with results of the screening test. Analyses showed the language subtests of the PSLST produced 9 false negatives or 13 percent of those tested passed the screening test but failed the validity test. Two false positives or three percent of the subjects failed the language subtests of the PSLST and passed the validity test. On the articulation subtest three false negatives or four percent of those tested passed the screening test but failed the validity test. One false positive or two percent of the subjects failed the articulation subtest of the PSLST and passed the validity test.

The language subtests had too large a proportion of false negatives to be considered a valid screening test of language abilities. It did not appear to test many of the language skills necessary for academic success that were tested on the UTLD, such as: auditory and visual memory; eye-hand coordination; and the ability to copy figures and follow directions. These skills are thought by the present investigator to be an important part of language screening. The articulation subtest, however, did effectively identify those children in need of further articulation testing and possibly intervention. 


\section{IMPIICATIONS}

Future Application

As noted in the previous discussion the articulation subtest of the PSLST did screen-out those children in need of further evaluation. In contrast, the language subtests did not effectively identify those children with language problems.

This investigator believes that a few changes could not only improve the articulation subtest but possibly also increase the validity of the language subtests. The major change proposed on the articulation subtest would be the testing of a few of the most frequently misarticulated sounds in all three positions. This could be done by either changing or adding a few more words to this section. Such a change would not only increase its reliability but would not significantly increase the administration time. The language subtests could be improved significantly by adding a few items which could more effectively tap a child's auditory and visual memory as well as some language skilis important for academic success. Tasks which might prove to be useful additions to the PSIST include: counting to ten; identifying body parts; repeating digits; drawing; and following commands. 


\section{Future Research}

More research is needed to discover the best way to evaluate a child's linguistic competence. Specifically, measures of a child's expressive language abilities and use of syntactic structures is needed. This would be useful not only for diagnostic evaluation but in screening children in large scale situations.

In addition, after making the above changes in the PSLST another study would be advisable utilizing either similar methods and procedures, or comparing it with another screening device. Variations in scoring the data also could be done, as well as analyzing it according to statistical procedures.

\section{CONCLUSION}

This study was undertaken to determine the validity of the PSLST. The articulation subtest was found to be a fairiy valid predictor of articulation ability. This investigator, however, found that the language subtests did not successfully identify children with language problems. Modifications were recommended which would increase the competence of the subtests in locating children with speech and/or language problems. 
$\bar{X} \bar{H} \bar{g} \overline{\mathrm{g}} \bar{\partial} \bar{O} \bar{I} \bar{I} \overline{\mathrm{g}} \overline{\mathrm{I}}$ 


\section{BIBLIOGRAPHY}

Ainsworth, S., Speech Correction Methods. Englewood Cliffs, N.J.: Prentice Hall (1948).

Anderson, C. I., School Health Practice. St. Louis, Mo.: C. V. Mosby (1972) .

Battin, R., and Haug, C., Speech and Language Delay. Springfield, Illinois: Charles C. Thomas (1968).

Bell, T. H., Your Child's Intellect. Salt Lake City: Olympus Publishing Co. (1972).

Berry, M., Language Disorders of Children: The Bases and Diagnosis. New York: Appleton (I969).

Black, Martha E., Speech Correction in the Schools. Englewood Cliffs, N.J.: Prentice HaIl, Inc. (1964).

Bryngelson, B., and Glaspey, E., Speech in the Classroom (With Speech Improvement Cards). Chicago, IIIinois: scott $(1962)$.

Butler, Katherine, "Review of the Utah Test of Language Development, Revised edition." In Oscar Buros (Ed.), The Seventh Mental Measurements Yearbook, Vol. II. New Jersey: The Grypon Press (1972).

Darley, Frederic, Diagnosis and Appraisal of Communication Disorders. New Jersey: prentice HalI, Inc. (1964).

Diehl, C. E., and Stinnett, D. D., "Efficiency of Teacher Referral in a School speech Testing Program." J. Speech and Hearing Dis., 22, 113-117 (1959).

Dol.1, E: A., The Vineland Social Maturity Scale. Minneapolis: Arerican Guidance Service (1959).

Drunwricht, A., Van Natra, P., Camp, B., Frankenburg, Wm., and Drexler, H., "The Denver Articulation Screening Test." J. Speech and Hearing Dis., 38, 3-14 (1973).

Dunn, I. J., Peabody Picture Vocabulary Test. Minneapolis: Imerican Guidance Service (I956). 
Ervin-Tripp, S. M., "Imitation and Structural Changes in Children's Language." In E. H. Lennenberg (Ed.), New Directions in the Study of Language. Cambridge: M.I.T. Press $(1 \overline{96})$.

Fearon, Ross E., "Guidelines for Speech Therapy in the Public Schools." Special Education Bulletin, Vo1. 4, No. 5C. Maine: ERIC MiCrofilm (1967).

Fisher, H., and Logemann, J., The Fisher-Logemann Test of Articulation Competence. Boston: Houghton Mifflin Co. (1971).

Fluharty, Nancy Buono, "The Design and Standardization of a Speech and Language Screening Test for Use with Preschool Children." J. Speech and Hearing Dis., 39, 75-88 (1974).

Gesell, A. L., and Amtruda, D. S., Developmental Diagnosis. New York: Hoeber (1941).

Goldman, R., and Fristoe, M., The Goldman-Fristoe Test of Articulation. Minnesota: American Guidance Service (1969).

Hamilton, Patricia, Validation of the Oregon School Entrance Speech Screening Test. (Unpublished Master's Thesis). Portland, Oregon: Portland State University (1974).

Hannah, Elaine P., and Gardner, Julie 0., Preschool Language Screening Test. California: Joyce Publications (1974).

Irwin, Ruth Becky, Speech and Hearing Therapy. Pittsburgh: Stanwix House (1965).

Jenkins, Edna, and Lohr, Frances, "Severe Articulation Disorders and Motor Ability." J. Speech and Hearing Dis., 29, 286-292 (1969).

Johnson, w., et al., Speech Handicapped School Children. New York: Harper and Row (1967).

Johnson, W., et al., Speech Handicapped School Children. New Yor $\bar{k}$ : Harper and Row (1948).

Kirk, S. A., McCarthy, J. J., and Kirk, W. D., Illinois Test of Psycholinguistic Abilities. Urbana, Illinois: University of Illinois Press (1968). 
Lee, L., Northwestern Syntax Screening Test. Evanston, Illinois: Northwestern University Press (1971).

MCNeil1, David, "Developmental Psycholinguistics." In Frank Smith and P. Miller (Eds.)., The Genesis of Language. Cambridge: M.I.I'. Press (I966).

Mecham, M., et al., Utah Test of Language Development. Salt Lake City, Utah: Communications Research Institute (1967).

Mecham, M., et al., "Use of the Utah Test of Language Development for Screening Language Disabilities." I. Learning Disabilities, 6, No. 7, 65-68 (1973).

Mecham, M., Verbal Language Development Scale. Minnesota: American Guidance Service (1959).

Menyuk, P., The Acquisition and Development of Language. Englewood Cliffs, N.J.: Prentice-Hall, Inc. (1971).

Monsees, $E$. , and Berman, C., "Speech and Language Screening in a Summer Headstart Program." I. Speech and Hearing Dis., 33, 121-126 (1968).

Nichols, A. C., "Public School speech and Hearing Therapy." In R. W. Rieber and R. S. Brubaker (Eds.), Speech Pathology. Amsterdam: North Holland Publishing Co. $(1966)$.

Pendergast, K., et al., photo Articulation Test. Chicago, rllinois: The King Co. (1965).

Perkins, W. H., Speech Pathology: An Applied Behavioral Science. St. Louis, Mo.: C. $\bar{V}$. Mosby Co. (1971).

Prahl, Harriet M., and Cooper, B., "Accuracy of Teacher Referral of Speech Handicapped Children." ASHA, 6, 393 (1964).

Prins, T., "Motor and Auditory Abilities in Different Groups of Children with Articulatory Deviations." J. Speech and Hearing Res., 5, 161-169 (1962).

Pronovost, W., "Case Selection in the Schools: Articulatory Disorders." Language, Speech and Hearing Services in

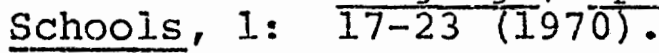


Prutting, Carol A., Gallagher, Tanga M., Mulac, Anthony, "The Expressive Portion of the NSST Compared to a Spontaneous Language Sample." J. Speech and Hearing Dis., 40, 40-47 (1975).

Rieber, R. W., and Brubaker, R. S. (Ed.), Speech Pathology. Amsterdam: North-Holland Publishing Co. (1966).

Roe, V., Hanley, C., Crotty, C., and Meyper, I., "Public School speech and Hearing Services, Clinical Practice: Diagnosis and Measurement." J. Speech and Hearing. Dis., Monograph Suppl., 8, 50-58 (1961).

Sanders, I. J., Procedure Guides for Evaluation of Speech and Language Disorders in Chilaren. Danvilie, Ill.: The Interstate Printers and Publishers, Inc. (1972).

Schoolfield, I., Better Speech and Better Reading. Magnolia, Mass.: Expression (1951).

Shipley, E., Smith, C., and Gleitman, L., A Study in the Acquisition of Language: A Free Response to Command. University of Iowa studies in Child Welfare, $\frac{1}{3(1926)}$.

Sommers, Ronald K., "Case Finding, Case Selection, and Case Load." In Ronald Van Hattum (Ed.), Clinical Speech in the Schools. Springfield, I11.: Charles C. Thomas (19 $\overline{69)}$.

Suydam, V. R., "Speech Survey Methods in Public Schools." J. Speech and Hearing Dis., 13, 51-54 (1948).

Task Force Reports, "Scheduling and Screening Procedures in Schools." In Language Speech and Hearing Services in the Schools, vol. 3-4, $\overline{100-119}$ (19 $\overline{72-1973)}$.

Templin, M., Certain Ianguage Skills in Children. MinneapoIis: University of Minneapolis Press (1957).

Templin, M., and Darley, F. I., The Templin-Darley Tests of Articulation (2nd ed.). Iowa City: University of IOWE (1969).

Terman, L. M., and Merrill, Maude, A., A Stanford-Binet Intelligence Scale. Boston: Houghton-Miffiin (1960).

Winitz, Harris, Articulatory Acquisition and Behavior. New York: Appleton-Cen tury-Crofts $(\overline{19} 6 \overline{9)}$. 
Wright, Revilla, and Levin, Barbara, "A Preschool Articulation and Language Screening for the Identification of Speech Disorders." Washington, D.C.: Office of Fducation, ERIC Microfilm (1971).

Zimmerman, Iralee, Steiner, Violette, and Evatt, Roberta, Preschool Language Scale. Ohio: Charles E. Merrill Publishing Co. (1969). 
$\bar{s} \bar{g} \bar{I} \bar{a} \bar{N} \bar{g} \bar{d} \bar{\forall}$ 


\section{APPENDIX A}

\section{PERMISSION REQUEST}

\section{Dear Parent:}

I am a graduate student at Portland state University and I'm studying the effectiveness of a speech and language test used this Fall during the kindergarten screening program at your school. I have the approval of the Portland Public Schools, and with your permission, I would like to talk with your child and obtain a language sample.

In no way will your child's name be used in this study. Will you please help me by signing this slip and pinning it to your child's clothing. The teacher will give it to me.

Parent's Signature

Thank you,

Susan Packouz

Graduate Student-PSU 


\section{APPENDIX B}

\section{PRESCHOOL SPEECH AND LANGUAGE SCREENING TEST}

(Fluharty - JSHD, February, 1974)

NAME

B.D.

SCHOOL

Score: (Put score on blank and circle items below norm.) ARTICULATION COMPREHENSION REPETITION

Section A:

Child verbally names objects. Present each item with "What is this?" No. 15 can be elicited with the question "Do you like jelly?" or "Are you a boy/girl?"

\begin{tabular}{lccc} 
OBJECT & $\begin{array}{c}\text { IDENTIFY } \\
(+ \text { Or } 0)\end{array}$ & FIRST PHONEME & SECOND PHONEME \\
\hline 1. hat & $/ \mathrm{h} /$ & $/ \mathrm{t} /$ \\
\hline 2. bag & $/ \mathrm{b} /$ & $/ \mathrm{g} /$ \\
\hline 3. sock & $/ \mathrm{s} /$ & $/ \mathrm{k} /$ \\
\hline 4. knife & $/ \mathrm{n} /$ & $/ \mathrm{f} /$ \\
\hline 5. teeth & $/ \mathrm{t} /$ & $/ \theta /-/ \mathrm{f} / \mathrm{black}$ dialect $)$ \\
\hline 6. pencil & $/ \mathrm{p} /$ & $/ \mathrm{n} /$ \\
\hline 7. windiow & $/ \mathrm{w} /$ & $/ \mathrm{d} /$ \\
\hline 8. comb & $/ \mathrm{k} /$ & $/ \mathrm{g} /$ \\
\hline 9. ring & $/ \mathrm{r} /$ & $/ \mathrm{z} /$ \\
\hline 10. shoes & $/ \mathrm{s} /$ & $\mathrm{m}$ \\
\hline
\end{tabular}


IDENTIFY

OBJECT

$(+$ or 0$)$

FIRST PHONEME

SECOND PHONEME

11. Leaves

/I/

$/ \mathrm{v} /$

12. chair

$|+5|$

$|x|$

13. feather

$|f /| \delta /-/ d /$ (black dialect)

14. jeliy

$\mid d z$

15. yes

$\mid j /$

$11 /$

1 pt. for each item correctly named

1 pt. for each correctly articulated phoneme.

VOCABULARY SCORE

ARTICULATION SCORE

Section B:

$(+=$ correct, $0=$ incorrect $)$

1. Have leaf, 2 pencils (red, yellow) and 2 bags on table.

Ask: "Is the leaf on the table?"

(Child's response is yes or no)

2. Remove leaf from the table.

"Show me: 'You are opening your mouth.'"

(Child opens mouth)

3. "Show me: 'The pencil is yellow.".

(Child points)

4. Remove pencils, display rings.

"Show me: The bag is paper."

(Child points)

5. Put one ring on paper bag; other in plastic bag. (Child points)

6. Remove rings, bags and display 2 combs.

"Show me your sock."

(Child points)

7. Put one comb on the floor, the other remains on the table.

"Show me (testee's name) is coughing."

(Child coughs) 
8. Display feather, shoe, hat.

"Show me: The comb isn't on the table." (Child points)

9. Ask: "Where is the feather?"

(Child points or stares)

10. Ask: "Take the shoe and the hat."

(Child must take)

Score 1 pt. for each item correctly performed. COMPREHENSION SCORE

Section C:

Clinician shows pictures and models sentences, child repeats. Place + on line if sentence is correctly repeated and 0 if incorrectly repeated. Cross out omitted items and record substituted responses.

1. The girls have the presents.

2. The man is a football player.

3. The baby is little.

4. They are walking.

5. The bus is here.

6. That is her cat.

7. The man can't reach.

8. The man said, "Who is it?"

9. The boy said, "Blow hard!"

10. The ice cream fell.

REPETITION SCORE

CUT-OFF SCORES

AGE IDENTIFICATION ARTICULATION COMPREHENSION REPETITION

2 years 9

3 years

11
18

19
4

6
3

4 


\section{CUT-OFF SCORES}

AGE

IDENTIFICATION ARTICULATION COMPREHENSION REPEITTION

4 years

12

13

21

25

6 years

14

26

7

8

6

8

8 


\section{APPENDIX C \\ UTAH TEST OF LANGUAGE DEVEIOPMENT}

I - II Years

1. Responds to narne and 'no-no.'

2. Follows simple instructions.

3. Marks with pencil or crayon.

4. Recognizes names of common objects.

5. Recognizes parts of body when named.

6. Recognizes parts of body (cont.).

7. Identifies common pictures when named.

8. Word combinations of two or more.

II - III Years

9. Names common pictures.

10. Names common pictures (cont.).

11. Can repeat two digits.

12. Responds to simple commands.

13. Identifies action in pictures.

14. Names one color.

15. Receptive vocabulary.

III - IV Years

16. Can repeat three digits.

17. Says full name.

18. Names common pictures.

19. Says at least one nursery rhyme.

20. Can copy cross.

IV - V Years

21. Names colors.

22. Can repeat four digits.

23. Carries out three commissions.

24. Can repeat a twelve-syllable sentence.

25. Draws with pencil or crayon.

V - VI Years

26. Can copy a square.

27. Prints simple words. 
28. Receptive vocabulary.

VI - VII Years

29. Names penny, nickel, and dime.

30. Writes numbers to the thirties.

31. Can tell a familiar story.

32. Reads words on pre-primer level.

33. Recites numbers from one to fifty.

34. Can copy a diamond.

VII - VIII Years

35. Receptive vocabulary.

36. Names quarter, half-dollar, and dollar.

37. Can repeat five digits.

38. Can name the days of the week.

VIII - $\mathrm{X}$ Years

39. Can repeat 16 syllable sentence.

40. Can write cursively with pencil.

41. Can rhyme words.

42. Can repeat 4 digits reversed.

43. Receptive vocabulary.

$\mathrm{X}-\mathrm{XV}$ Years

44. Can repeat 6 digits.

45. Can repeat a 20 syllable sentence.

46. Can repeat 5 digits reversed.

47. Receptive vocabulary

48. Can repeat 5 mono-syllable words.

49. Can repeat difficult sentence from memory.

50. Receptive vocabulary.

51. Is oriented on directions.

COMMENTS : 
TABLE FOR CONVERTING TOTAL RAW SCORES

TO ILANGUAGE-AGE-EQUIVALENTS

(In Years and Months)

\begin{tabular}{|c|c|c|c|c|c|}
\hline $\begin{array}{l}\text { Raw } \\
\text { Score }\end{array}$ & $\begin{array}{c}\text { Language } \\
\text { Age }\end{array}$ & $\begin{array}{l}\text { Raw } \\
\text { Score }\end{array}$ & $\begin{array}{c}\text { Language } \\
\text { Age }\end{array}$ & $\begin{array}{l}\text { Raw } \\
\text { Score }\end{array}$ & $\begin{array}{c}\text { Language } \\
\text { Age }\end{array}$ \\
\hline 1 & $0-9$ & 18 & $3-5$ & 35 & $7-1$ \\
\hline 2 & $1-1$ & 19 & $3-8$ & 36 & $7-3$ \\
\hline 3 & $1-4$ & 20 & $3-10$ & 37 & $7-7$ \\
\hline 4 & $1-6$ & 21 & $4-1$ & 38 & $7-11$ \\
\hline 5 & $1-7$ & 22 & $4-4$ & 39 & $8-3$ \\
\hline 6 & $1-9$ & 23 & $4-7$ & 40 & $8-8$ \\
\hline 7 & $1-10$ & 24 & $4-9$ & 41 & $9-0$ \\
\hline 8 & $2-0$ & 25 & $5-0$ & 42 & $9-5$ \\
\hline 9 & $2-2$ & 26 & $5-3$ & 43 & $9-11$ \\
\hline 10 & $2-3$ & 27 & $5-6$ & 44 & $10-5$ \\
\hline 11 & $2-5$ & 28 & $5-10$ & 45 & $10-11$ \\
\hline 12 & $2-6$ & 29 & $6-1$ & 46 & $12-0$ \\
\hline 13 & $2-8$ & 30 & $6-3$ & 47 & $12-7$ \\
\hline 14 & $2-9$ & $3 I$ & $6-5$ & .48 & $13-5$ \\
\hline 15 & $2-11$ & 32 & $6-6$ & 49 & $14-6$ \\
\hline 16 & $3-1$ & 33 & $6-8$ & 50 & $15-4$ \\
\hline 17 & $3-3$ & 34 & $6-11$ & 51 & $16-0$ \\
\hline
\end{tabular}


APPENDIX D

PHOTO ARTICULATION TEST

Sound

Photograph

12 3. Vowels, Diph. Comments

s saw, pencil, house

JU house

s bl spoon, skates, stars

$z$ zipper, scissors, keys

5 shoe, station, fish

u shoe

t5 chair, matches, sandwich

dy jars, angels, orange

$t$ table, potatoes, hat

ge. hat

d dog, ladder, bed

$\supset \operatorname{dog}$

$n$ nails, bananas, can

o bananas

1 lamp, balloons, bell

$\varepsilon$ bell

I bl blocks, clock, flag

a blocks

$\theta$ thumb, toothbrush, teeth

i teeth

r radio, carrots, car

$r$ bl brush, crayons, train

e train

k cat, crackers, cake

$\delta-\partial \quad$ crackers

g gun, wagon, egg

$\wedge$ gun

f fork, elephant, knife

v vacuum, TV, stove

ju vacuum

p pipe, apples, cup

ZI pipe 
62

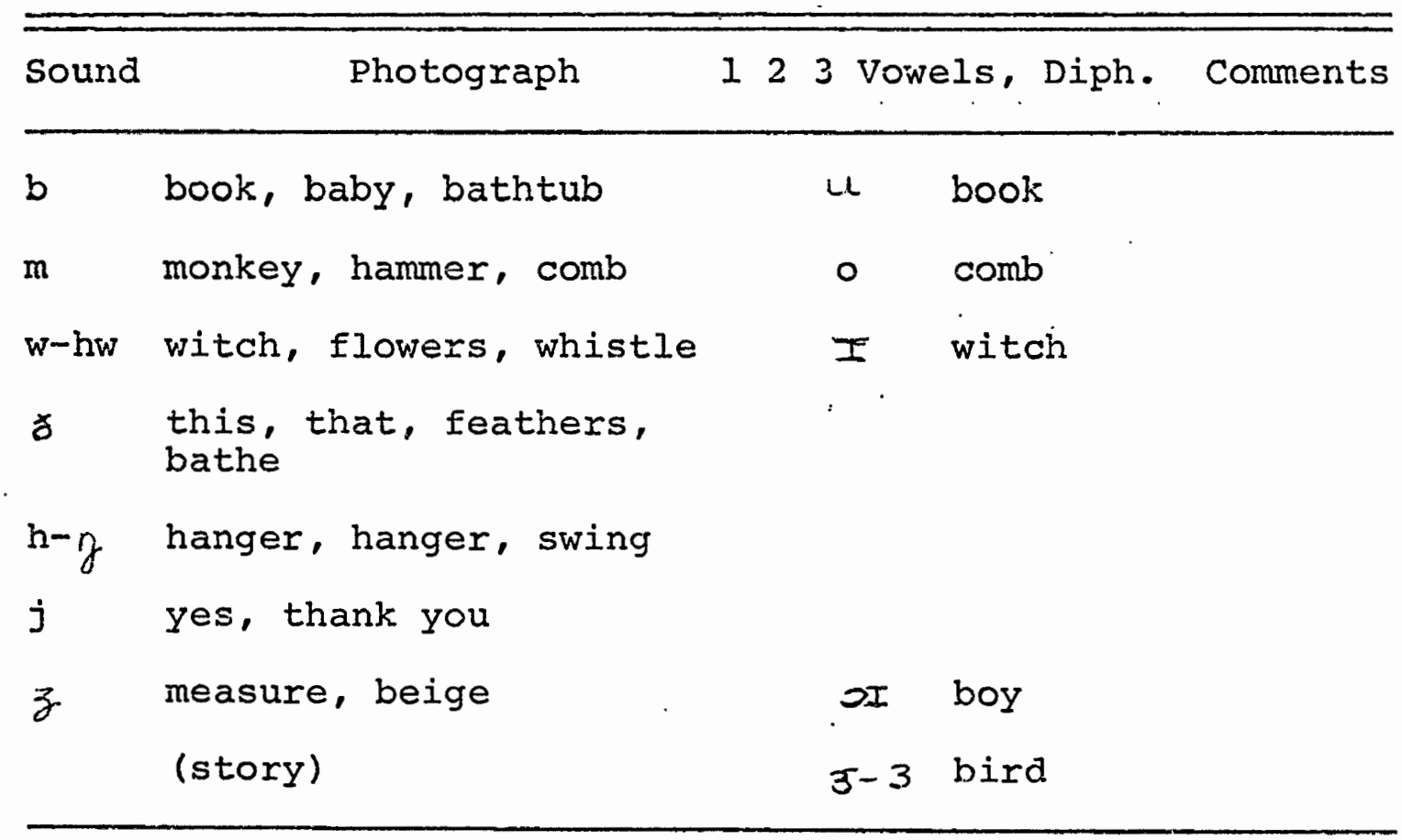




\section{APPENDIX E}

\section{RESULTS AND DISCUSSION OF THE FAII AND WINTER}

ADMINISTRATION OF THE PSLST

The original design of this study was to use the screening test administered in the Fall to compare with two diagnostic tests administered shortly thereafter. Due to unforeseen difficulties regarding the necessary approvals for testing subjects, it was impossible to use this original screening test administered in the Fall as a comparison instrument. This earlier administration of the test, however, did allow for demonstrating whether or not the PSLST showed growth in a subject's abilities over time.

\section{LANGUAGE SUBTEST RESULTS}

Table 1 represents the results of the language subtests.(i.e., repetition, comprehension and vocabulary) administered in the Fall and those administered in the Winter. It shows the number and percentage of subjects: 1) who passed or failed both tests; 2) who failed the Fall and passed the Winter testing; and 3) who failed the Winter and passed the Fall testing.

From Table 1 it can be noted that one was a false negative, thirteen were false positives and fifty-four sub- 
jects received similar scores on both tests.

Table 1

LANGUAGE SUBTEST RESUI,TS

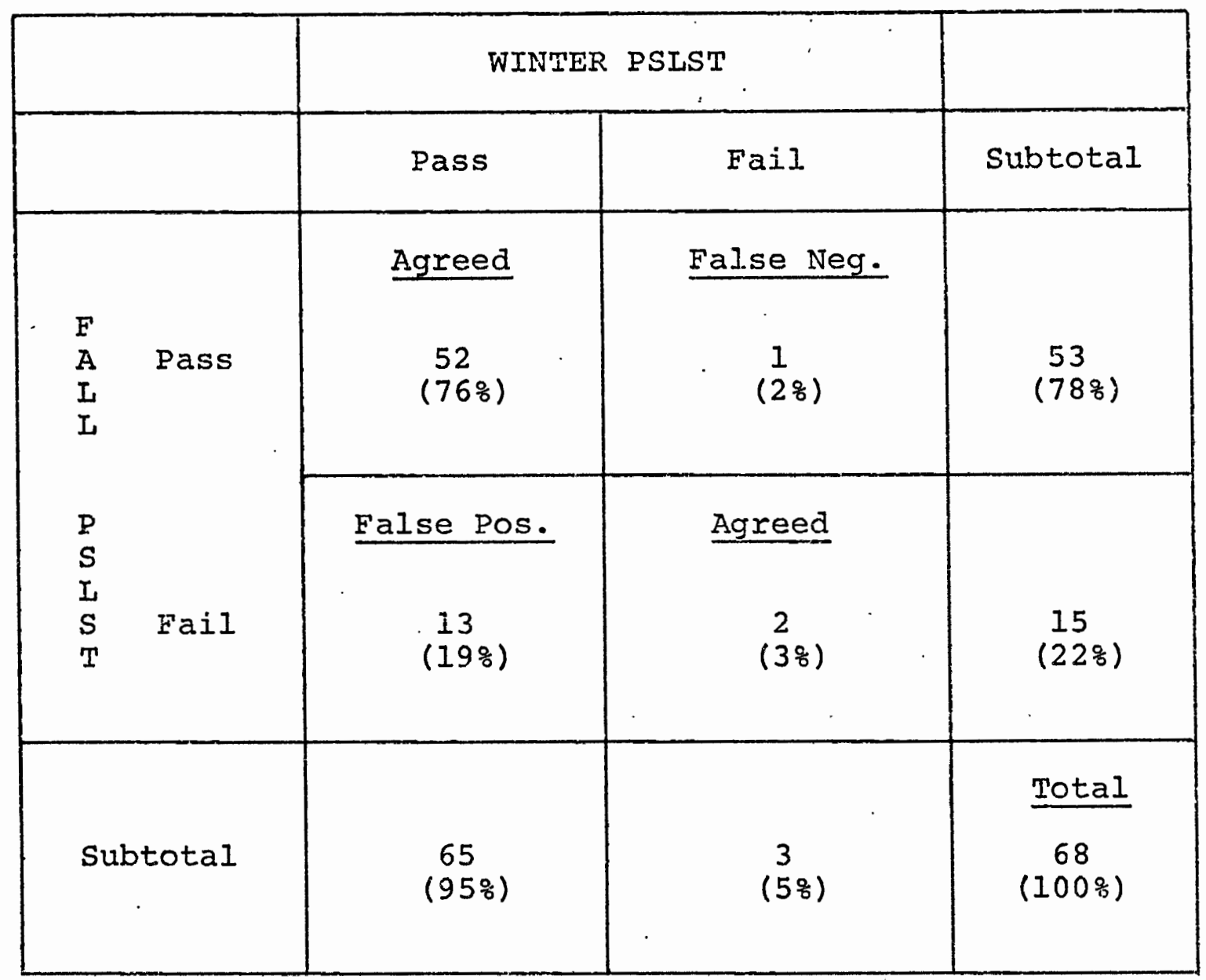

ARTICULATION SUBTEST RESULTS

Table 2 is the product of the articulation subtest of the PSLST given in the Fall and that given in the winter. It shows the number and percentage of subjects who: 1) passed or failed both tests; 2) failed the Fall test and 
passed the Winter; and 3) who failed in the winter and passed in the Fall.

Table 2

ARTICULATION SUBTEST RESULTS

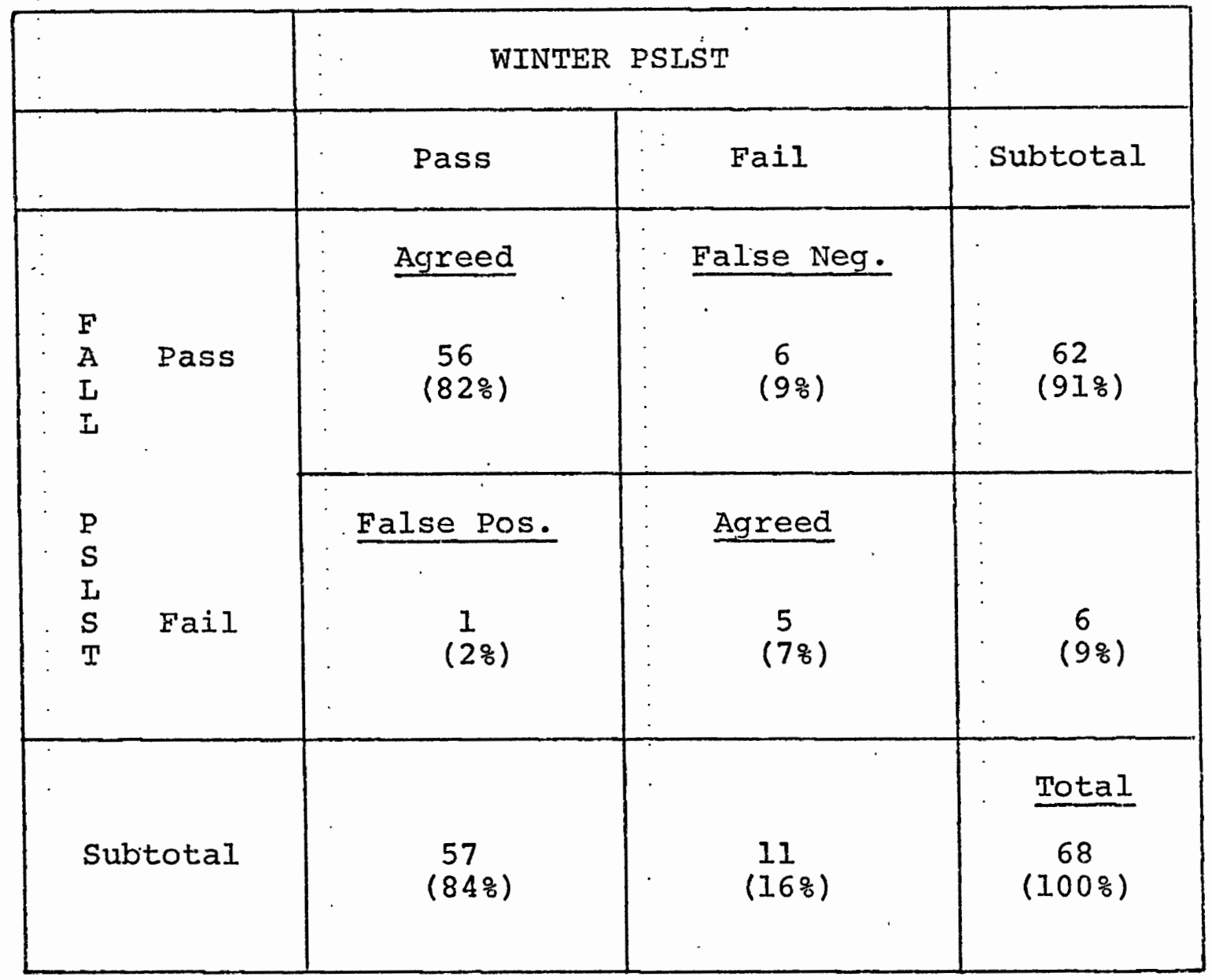

As seen in Table 2, six of the subjects were false negatives, one was a false positive and sixty-one were in agreement on both tests. 


\section{DISCUSSION}

It can be noted above that these results do reveal some interesting information regarding this test. Specifically, the results from the language subtest. show that the PSLST does show the growth in a child's language abilities over a six month period of time. This is shown by the smaller number of children who failed the language subtests in the winter. Fifteen or twenty-two percent of the children failed the language subtests in the fall while only three or five percent failed in the winter. These results would appear to show the screening test may be sensitive to language growth over time. Clearly, as a result of school instruction each child should have shown an increase in language abilities.

The articulation subtest of the PSLST, however, does not show the same trends (see Table 2). In the Fall six or nine percent of the subjects failed the screening test while in the Winter eleven or sixteen percent of the subjects were failing. This is thought to be the result of two factors. First, in the Fall the screening test was administered by the present examiner and four other trained clinicians. In the winter this examiner did all of the testing. Naturally, there would be some variation as a resilt of the various examiners working during the Fall. 
Winitz (1969) points out that each-examiner may introduce certain systematic biases into articulation testing. They have typically had training which creates expectancies concerning the type and distribution of errors. This factor plus the second one which is the increased competence of the present investigator, are probably the explanation for the above results. 